\title{
Opioid analgesics in the management of neuropathic pain
}

\author{
Dwight Moulin MD
}

\section{Moulin. \\ Opioid analgesics in the management of neuropathic pain. Pain Res Manage 2000:5(1):89-91.}

The role of antidepressants and anticonvulsants in the management of neuropathic pain has been well established. However, up to 50\% of patients obtain inadequate pain relief with the use of either or both of these agents; in this subpopulation, an opioid analgesic may be beneficial. There is clear evidence that opioid analgesics are efficacious in the management of neuropathic pain, but there is controversy as to the balance between analgesia and adverse effects. Opioid treatment may require higher doses than other kinds of drug therapies, thereby increasing the risk of opioid-related side effects. Psychological dependence or addiction, however, is not usually an issue in pain management with opioid analgesics.

The extant literature strongly suggests the trial of an opioid analgesic in the management of neuropathic pain if adjuvant analgesics fail to provide adequate pain control. Failure of one opioid warrants a trial of another opioid because their effectiveness can vary among patients; the results are based on physiochemical properties of the drug and idiosyncratic reactions of the patient. Neuropathic pain can be a difficult problem to manage, and sometimes the use of an opioid analgesic can make the difference between bearable and unbearable pain so that patients can get on with their lives.

\section{Analgésiques opioïdes et traitement des douleurs névropathiques}

RÉSUMÉ: Le rôle des antidépresseurs et des antiépileptiques est bien connu dans le traitement des douleurs névropathiques. Cependant, jusqu'à $50 \%$ des patients ne connaissent pas de soulagement satisfaisant des douleurs avec l'une ou l'autre de ces classes de médicaments, ou les deux; c'est alors que les analgésiques opiö̈des peuvent s'avérer utiles. Il ne fait aucun doute que ces derniers assurent un traitement efficace des douleurs névropathiques, mais il une existe une controverse quant à l'équilibre entre l'analgésie et les effets secondaires indésirables. Le traitement aux analgésiques opioïdes peut exiger des doses plus élevées que les autres sortes de médicaments, d'où risque accru d'effets secondaires liés aux opioïdes. Toutefois, ceux-ci n'entrânent généralement pas de dépendance psychologique ou de toxicomanie dans les cas de traitement de la douleur. Ainsi, il est fortement recommandé, dans la documentation encore aujourd'hui, de faire l'essai d'un analgésique opioïde dans le traitement des douleurs névropathiques si les autres médicaments adjuvants n'ont pas donné de résultats satisfaisants. D'ailleurs, on suggère de faire l'essai d'un autre opioïde en cas d'échec du premier parce que l'efficacité de ces médicaments varie d'un patient à l'autre; les résultats dépendent des propriétés biochimiques du produit et des réactions idiosyncrasiques des patients. Les douleurs névropathiques peuvent s'avérer difficiles à traiter, et parfois l'utilisation d'un analgésique opioïde peut rendre tolérable une douleur intolérable et permettre ainsi aux patients de poursuivre leur vie.

Key Words: Neuropathic pain; Opioid analgesics

$\mathrm{T}$ he treatment of pain associated with nerve injury, as seen in diabetic neuropathy and postherpetic neuralgia, must account for the three cardinal symptoms of neuropathic pain that are present to variable degrees in most patients. These sensations usually arise from the territory of the injured nerve but can radiate into adjacent, normally innervated areas. Constant, burning dysesthetic pain is common and is often described as if the involved area is 'on fire'. The second major symptom of neuropathic pain is paroxysmal pain that usually is fleeting, intense and lancinating. It can be spontaneous, or evoked by movement or tactile stimulation. The third symptom is the aberrant perception of pain in response to an innocuous stimulus (allodynia). Light touch, warmth and cold may all be perceived as unbearable pain.

The role of tricyclic antidepressants and anticonvulsants in the management of neuropathic pain has been well established $(1,2)$. However, the role of opioid analgesics in the management of neuropathic pain has been viewed as controversial since the 1988 report by Arner and Meyerson (3), which concluded that opioids have no analgesic action in this 


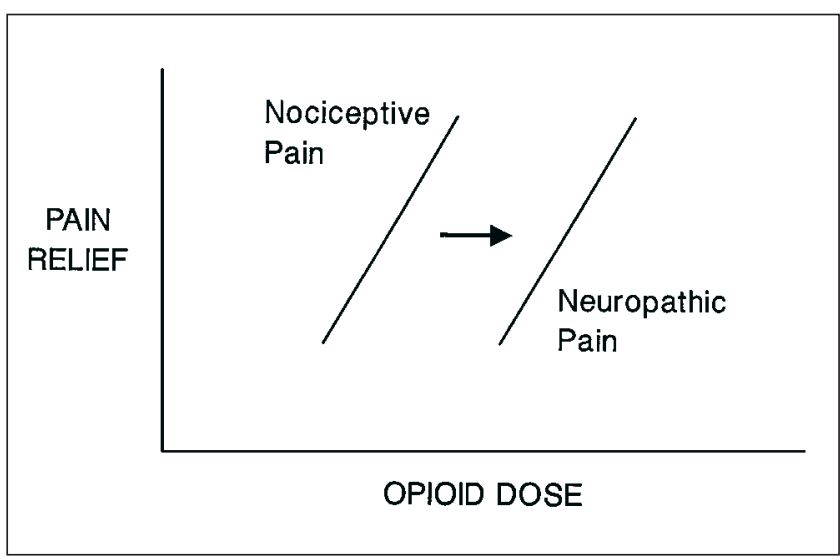

Figure 1) Opioid dose-response curves for nociceptive and neuropathic pain

condition. This study was criticized because all of the neuropathic patients had long histories of "severely incapacitating pain which had resisted all previous treatments" (3) including opioids. More recent studies suggest a continuum of opioid responsiveness in which patients with neuropathic pain may require higher drug doses than patients with nociceptive pain to experience analgesia. The evidence comes from studies involving brief opioid infusions $(4,5)$ that suggest that neuropathic pain responds to opioid drugs in a classic dose-dependent fashion, but that there is a shift to the right in the dose-response curve (Figure 1); ie, more of the drug is required for the same analgesic effect with an increased risk of opioid-related side effects. This contention is supported in a recent, randomized controlled postoperative study that examined pain relief following thoracotomy using intravenous buprenorphine (6). The primary outcome measure was $50 \%$ pain relief. Pain relief was assessed in the immediate postoperative period when the pain was largely nociceptive and one month after surgery in the same 21 patients who developed post-thoracotomy neuropathic pain. The dose of buprenorphine required to provide $50 \%$ pain relief for patients with neuropathic pain was almost twice the dose required for patients with nociceptive pain.

\section{EVIDENCE OF EFFICACY FROM RANDOMIZED, CONTROLLED TRIALS}

The efficacy of opioid analgesics in the management of neuropathic pain has been shown by several controlled trials. A double-blind crossover study comparing intravenous infusions of morphine with saline placebo in patients with postherpetic neuralgia found that morphine significantly reduced pain intensity (7). A similarly designed study (8) in patients with mixed neuropathic pain conditions found that morphine reduced affective pain ratings. Dellemijn and Vanneste (9) studied 50 patients with mixed peripheral neuropathic pain states by comparing intravenous infusions of fentanyl with either saline placebo or benzodiazepine diazepam. Fentanyl reduced the unpleasantness of pain intensity relative to both control groups, although diazepam almost produced as much sedation as fentanyl (9).
There is a single, recent report of a placebo controlled trial of a major oral opioid analgesic for neuropathic pain. Watson and Babul (10) described a crossover trial of sustainedrelease oxycodone in 50 patients with postherpetic neuralgia. Outcome analysis in the 38 patients who completed the study revealed an almost $40 \%$ reduction in pain intensity relative to placebo in the last week of the four-week treatment period. Scores for steady pain, brief pain and touch-evoked pain were all lower relative to placebo treatment. Constipation, nausea and sedation were significantly more common during oxycodone therapy.

\section{EFFICACY VERSUS EFFECTIVENESS}

Efficacy can be defined as evidence of benefit in a rigorously designed, randomized, controlled trial with clear outcome measures in the short term. Evidence of efficacy for opioids in the management of neuropathic pain is probably better validated than for any other type of chronic noncancer pain. However, this is not the same as effectiveness that refers to evidence of benefit in the long term in the context of real life experience. Apart from opioid-related side effects, the safety of driving and the risk of psychological dependence or addiction are always concerns with opioid therapy. Only one randomized, controlled trial has addressed the former issue. A controlled trial involving cancer patients showed no significant difference in psychomotor driving skills in opioid-naive patients and patients on oral morphine at a mean daily dose of $209 \mathrm{mg}$ (11). The risk of addiction in this patient population is probably very low given extensive survey data accumulated over the past 25 years. In several studies involving almost 25,000 patients without a history of dependence, there were only seven cases of iatrogenic addiction (12). These observations are reassuring. However, a two-year follow-up study (9) of patients who participated in the trial of intravenous fentanyl for neuropathic pain illustrates the potential limitations of long term opioid therapy. At the end of two years, only $10 \%$ to $20 \%$ of patients perceived a persistent clinical benefit (13). Therefore, it remains to be shown that opioids provide a favourable balance between analgesia and adverse effects over the long term in the management of neuropathic pain.

\section{OPIOIDS VERSUS ADJUVANT ANALGESICS IN THE MANAGEMENT OF NEUROPATHIC PAIN}

The place of opioid analgesics relative to adjuvant analgesics in the management of neuropathic pain is not clear. There have been no head to head trials to establish treatment preference. Antidepressants and anticonvulsants are recognized as providing first-line treatment. However, systematic reviews show little to choose between these classes of agents $(1,2)$. Approximately one in three patients with neuropathic pain experiences at least 50\% pain relief from either an antidepressant or an anticonvulsant. Even with combined treatment, up to $50 \%$ of patients who may benefit from the addition of an opioid analgesic may be left with inadequate pain relief. 


\section{GUIDELINES FOR OPIOID USE IN THE TREATMENT OF NEUROPATHIC PAIN}

Many patients with neuropathic pain who have inadequate pain relief from antidepressants and anticonvulsants have also failed trials of minor opioids such as codeine. A reasonable starting dose of oral morphine in this setting is $10 \mathrm{mg}$ every $4 \mathrm{~h}$ or sustained-release morphine $30 \mathrm{mg}$ twice daily. A general rule of thumb is gradual dose titration in approximately $50 \%$ increments to a level of either pain relief or unacceptable side effects (14). Because tolerance can develop into side effects in the short term at any particular dose, dose titrations should probably take place at least one week apart. Failure of one opioid warrants a trial of another because opioid responsiveness can vary among individual patients, based on physiochemical properties of the drug and idiosyncratic reactions of the patient. Standard analgesic tables can be consulted to determine equivalent doses of various opioid analgesics (15).

Methadone is a synthetic opioid analgesic that may be particularly useful in the management of neuropathic pain because it has antagonistic properties of $N$-methyl-D-aspa-

\section{REFERENCES}

1. McQuay HJ, Tramer M, Nye BA, Carroll D, Wiffen PJ, Moore RA. A systematic review of antidepressants in neuropathic pain. Pain 1996;68:217-27.

2. McQuay H, Carroll D, Jadad AR, Wiffen P, Moore A. Anticonvulsant drugs for management of pain: a systematic review. BMJ 1995;311:1047-52.

3. Arner S, Meyerson BA. Lack of analgesic effect of opioids on neuropathic and idiopathic forms of pain. Pain 1988;33:11-23.

4. Jadad AR, Carroll D, Glynn CJ, Moore RA, McQuay HJ. Morphine responsiveness of chronic pain: double-blind randomised crossover study with patient-controlled analgesia. Lancet 1992;339:1367-71.

5. Portenoy RK, Foley KM, Inturrisi CE. The nature of opioid responsiveness and its implications for neuropathic pain: new hypotheses derived from studies of opioid infusions. Pain 1990;43:273-86.

6. Benedetti F, Vighetti S, Amanzio M, et al. Dose-response relationship of opioids in nociceptive and neuropathic postoperative pain. Pain 1998;74:205-11.

7. Rowbotham MC, Reisner-Keller LA, Fields HL. Both intravenous lidocaine and morphine reduce the pain of postherpetic neuralgia. Neurology 1991;41:1024-8.

8. Kupers RC, Konings H, Adriaensen H, Gybels JM. Morphine differentially affects the sensory and affective pain ratings in neurogenic and idiopathic forms of pain. Pain 1991;47:5-12. rtate (16). $\mathrm{N}$-methyl-D-aspartate receptors are known to play a role in the generation of central or deafferentation pain. Methadone is also attractive because it has excellent oral bioavailability, a duration of action of at least $8 \mathrm{~h}$ with repetitive dosing and availability at very low cost. However, it has a half-life of 24 to $36 \mathrm{~h}$, which mandates close observation during the titration phase. In addition, methadone is up to 10 times more potent than suggested by standard dose equivalency tables and should only be used in consultation with a pain specialist familiar with its use. Although there have been no controlled trials of methadone in the management of neuropathic pain, methadone treatment appears promising and warrants further investigation.

Neuropathic pain, apart from trigeminal neuralgia, is a difficult problem to manage. A realistic goal, in most cases, is to make the pain tolerable, and this should be communicated to the patient. Because adjuvant analgesics frequently fail to manage neuropathic pain, the use of an opioid analgesic with an acceptable side effect profile can sometimes make the difference between bearable and unbearable pain so that patients can get on with their lives.

9. Dellemijn PL, Vanneste JA. Randomized double-blind active-placebocontrolled crossover trial of intravenous fentanyl in neuropathic pain. Lancet 1997;349:753-8.

10. Watson CP, Babul N. Efficacy of oxycodone in neuropathic pain: a randomized trial in postherpetic neuralgia. Neurology 1998;50:1837-41.

11. Vainio A, Ollila J, Matikainen E, Rosenberg P, Kalso E. Driving ability in cancer patients receiving long-term morphine analgesia. Lancet 1995;346:667-70.

12. Portenoy RK. Opioid therapy for chronic nonmalignant pain: current status. In: Fields HL, Liebeskind JC, eds. Pharmacological Approaches to the Treatment of Chronic Pain. New Concepts and Critical Issues (Progress in Pain), vol 1. Seattle: IASP, 1994:247-87.

13. Dellemijn PL, van Duijn H, Vanneste JA. Prolonged treatment with transdermal fentanyl in neuropathic pain. J Pain Symptom Manage 1998; 16:220-9.

14. Jovey RD, Ennis J, Gardner-Nix J, et al. Use of opioid analgesics for the treatment of chronic non-cancer pain - A consensus statement and guidelines from the Canadian Pain Society. Pain Res Manage 1998;3:197-208.

15. Levy MH. Pharmacologic treatment of cancer pain. N Engl J Med 1996;335:1124-32.

16. Gannon C. The use of methadone in the care of the dying. Eur J Palliat Care 1997;4:152-8. 


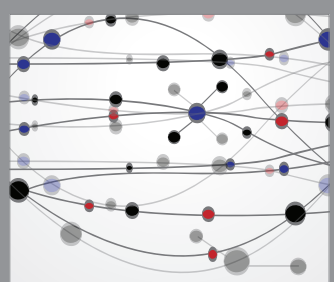

The Scientific World Journal
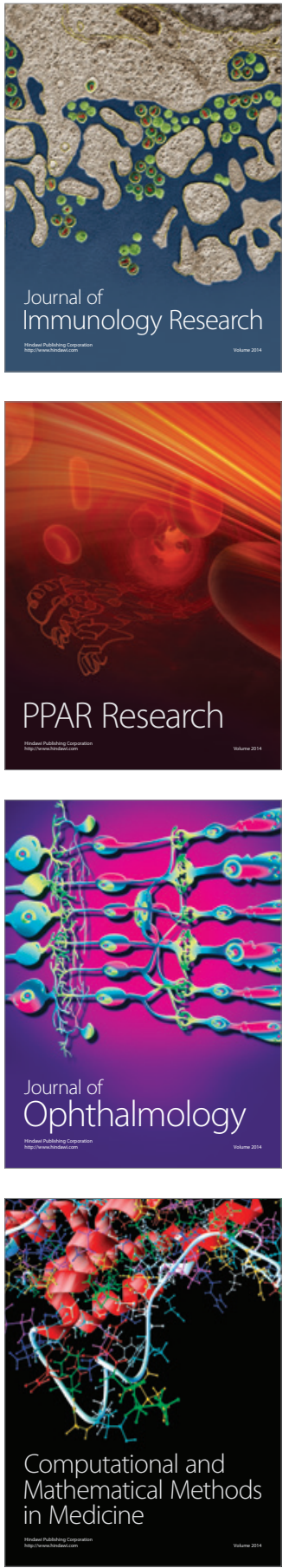

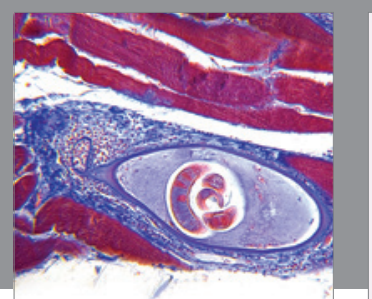

Gastroenterology Research and Practice

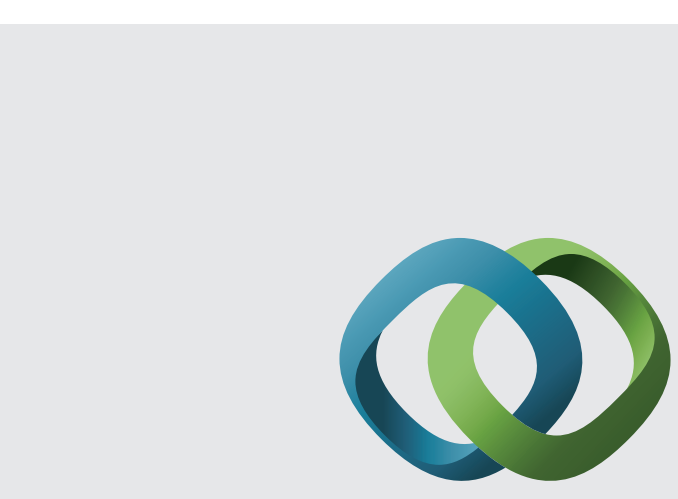

\section{Hindawi}

Submit your manuscripts at

http://www.hindawi.com
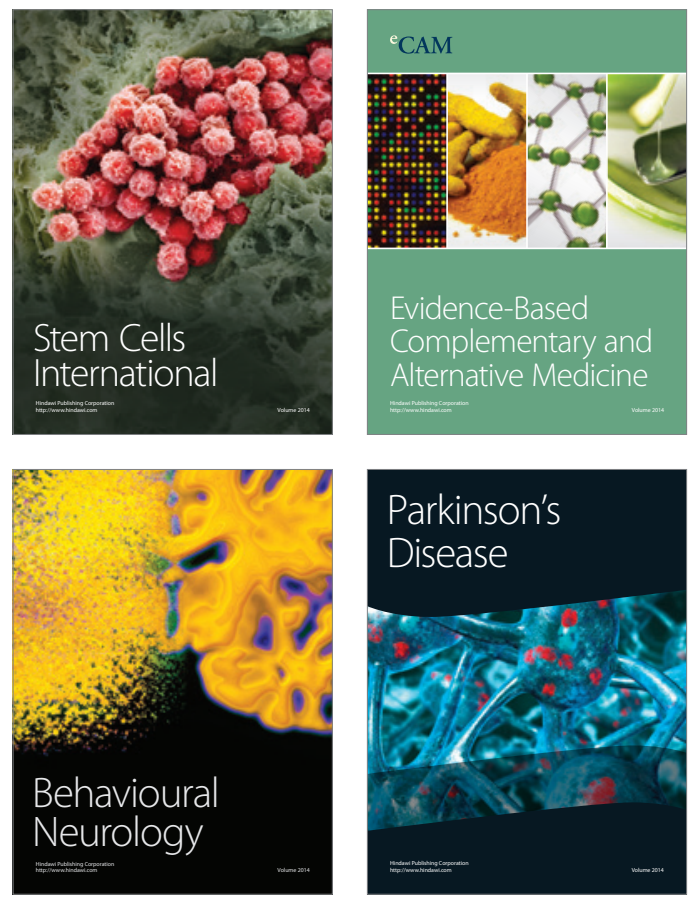
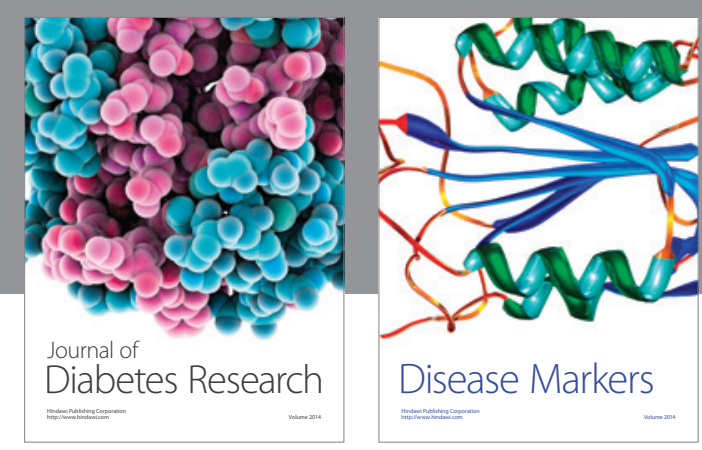

Disease Markers
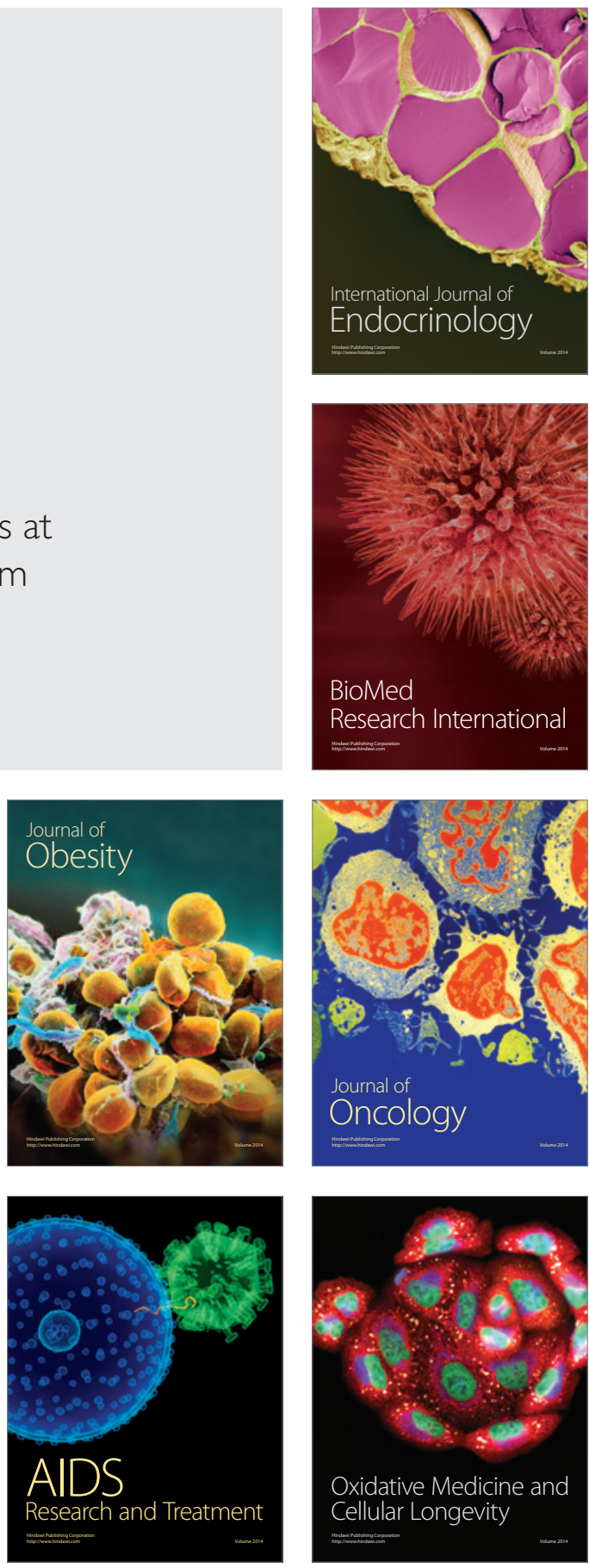